\title{
PTPN9 promotes cell proliferation and invasion in Eca109 cells and is negatively regulated by microRNA-126
}

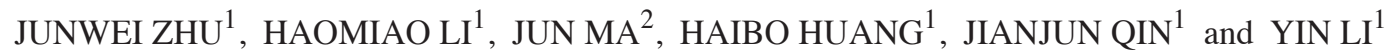 \\ ${ }^{1}$ Department of Thoracic Surgery, The Affiliated Tumor Hospital of Zhengzhou University, Zhengzhou, Henan 450008; \\ ${ }^{2}$ Department of Gastroenterology, The Second Affiliated Hospital of Zhengzhou University, \\ Zhengzhou, Henan 450014, P.R. China
}

Received September 11, 2015; Accepted April 13, 2017

DOI: 10.3892/ol.2017.6315

\begin{abstract}
Protein tyrosine phosphatase non-receptor type 9 (PTPN9), also named PTP-MEG2, is an important member of the protein tyrosine phosphatase family that is involved in variety of human diseases. However, the role of PTPN9 in esophageal squamous cell carcinoma (ESCC) remains to be established. The present evaluated the potential effect and underlying mechanism of action of PTPN9 in ESCC. Immunohistochemistry was performed to detect PTPN9 protein expression in 84 ESCC tumor specimens and 30 normal esophageal tissues. The association between positive expression of PTPN9 and clinicopathological features and prognosis was analyzed. The prognostic role of PTPN9 was further investigated using multivariate regression analysis. PTPN9-small interfering RNA and microRNA (miR-126)-mimics were transfected into Eca109 cells to construct PTPN9 silencing and an miR-126 ectopic expression cell model. Reverse transcription-quantitative polymerase chain reaction, western blot analysis, cell counting kit- 8 , Transwell assays and flow cytometry were used to investigate the role of PTPN9 in the process of ESCC progression and its potential downstream signaling pathway. Immunohistochemical analysis revealed that PTPN9 was upregulated in ESCC tumor specimens compared with normal esophageal tissues. The $\chi^{2}$ test indicated that positive expression of PTPN9 was correlated with tumor node metastasis stage, tumor classification and node classification. Patients with PTPN9 positive expression had shorter survival time, compared with those that were PTPN9 negative. Multivariate regression analysis with the Cox proportional hazards regression model revealed that PTPN9 expression was a prognostic factor of overall survival for patients with ESCC.
\end{abstract}

Correspondence to: Dr Yin Li, Department of Thoracic Surgery, The Affiliated Tumor Hospital of Zhengzhou University, 127 Dongming Road, Jinshui, Zhengzhou, Henan 450008, P.R. China E-mail: 1009828526@qq.com

Key words: esophageal squamous cell carcinoma, protein tyrosine phosphatase non-receptor type 9, microRNA-126, prognosis, proliferation, invasion, apoptosis
Using RNA interference, the present study demonstrated that knockdown of PTPN9 significantly suppressed cell proliferation and invasion in Eca109. Additionally, it was hypothesized that miR-126, described as a tumor suppressor in ESCC, may act at least in part via its inhibition of PTPN9 at the post-transcriptional level. To the best of our knowledge, this is the first study to demonstrate that PTPN9 is overexpressed in ESCC and associated with poor survival, and may therefore be important in the pathogenesis of ESCC.

\section{Introduction}

Globally, esophageal cancer is a highly common malignancy associated with significant mortality, with $\sim 6.5$ billion new cases and 400,200 mortalities in 2012 (1). In China, it has been ranked as the fifth and fourth highest tumor type for incidence and mortality, respectively (2). Esophageal squamous cell carcinoma (ESCC) remains the major histological subtype in China, accounting for $90 \%$ of newly diagnosed patients (3). When accompanied by low socioeconomic status, active tobacco and alcohol abuse, malnutrition, pulmonary comorbidities and secondary malignancies, the long-term survival rate is poor and requires improvement (4). Despite the improvements in therapeutic strategies, including surgical techniques and induction therapy, prior to or following surgery, biomarkers for tailored multimodal treatment with increased efficacy are required.

Protein tyrosine phosphatase non-receptor type 9 (PTPN9), also termed PTP-MEG2, is highly expressed in the brain, leukocytes and endocrine cells and is a cytoplasmic phosphatase that is hyperactivated in erythroid progenitors (5). PTPN9 is usually present in the cytoplasm and cell membrane of the majority of cells $(5,6)$. It is unique among the protein tyrosine phosphatases due to its $\mathrm{N}$-terminal Sec $14 \mathrm{p}$ homology domain, which is able to activate the enzyme of the phosphatase domain of PTPN9 via binding phosphoinositides $(7,8)$. PTPN9 is involved in numerous cellular processes, including cell proliferation, differentiation and migration through the regulation of signaling pathways (9). For example, it promotes secretory vesicle fusion (10), mediates insulin signaling in hepatocytes $(11,12)$, inhibits breast cancer cell growth (13-15) and regulates endothelial cell function (16). However, the role of PTPN9 in ESCC remains to be established. 
MicroRNAs (miRNAs) are a class of highly conserved, non-coding, small single-stranded RNAs of 22-25 nucleotides, which have been reported to serve important roles in a number of types of human disease $(17,18)$. Due to their sequences being complementary to specific sequences in transcripts, miRNAs negatively regulate gene expression by altering mRNA abundance at the post-transcriptional level, as well as allowing for transcription modification. Located at chromosome 9q34.3, an intron of EGF-like domain-containing protein 7 (EGFL7), miRNA (miR)-126 is associated with various human tumors (19). Commonly exhibiting tumor suppressive properties, miR-126 is expressed at a low level in numerous human malignances, including lung cancer (20), colon cancer (21), breast cancer (22), osteosarcoma (23) and gastric cancer (24). Repression of cancer cell proliferation (25), migration (26) and invasion (27) mediated by miR-126 can be achieved via targeting specific oncogenes, including phospoinositide 3-kinase, V-Ki-ras2 Kirsten rat sarcoma viral oncogene, EGFL7 and vascular endothelial growth factor (VEGF). In addition, reduced levels of miR-126 are an effective predictor of poor survival in patients with cancer $(20,28)$. A previous study indicated that miR-126 was able to negatively regulate erythropoietic development by targeting PTPN9 (29). However, the role of PTPN9 and the association between miR-126 and PTPN9 in ESCC has, to the best of our knowledge, never been investigated. Therefore, the present study aimed to investigate their potential roles in the development of ESCC.

\section{Materials and methods}

Patients and specimens. In total, 84 patients with ESCC were included in the present study. The inclusion criteria were as follows: i) Diagnosis of ESCC with histopathological identification; ii) no treatment received prior to surgery; iii) 7th edition of Union for International Cancer Control tumor-node-metastasis (TNM) classification system (30) was used for staging the tumor; iv) limited or extended surgical history including esophagectomy at the Department of Thoracic Surgery, Henan Tumor Hospital (Zhengzhou, China) between January 2008 and December 2009; v) detailed clinical records were available with follow-up duration extending until May 10th, 2014; vi) tumor specimens were frozen in liquid nitrogen and stored at $-80^{\circ} \mathrm{C}$ following surgical resection, in order to perform immunohistochemistry (IHC). Specimens were obtained with the informed consent of patients. The present study was approved by the Ethics Committee of Henan Tumor Hospital. Post-surgical follow-up was conducted every 3 months for the first 2 years, every 6 months between the 3rd and 6th year, or until patient mortality. The overall survival rate was calculated as the period between surgery and the date of mortality or final observation.

Cell line and cell culture. Obtained from the Cell Bank of the Tumor Hospital of the Chinese Academy of Medical Sciences (Beijing, China), the Eca109 human ESCC cell line was cultured in RPMI-1640 supplemented with $10 \%$ fetal bovine serum (FBS; both from Thermo Fisher Scientific, Inc., Waltham, MA, USA) and $100 \mathrm{U} / \mathrm{ml}$ penicillin-streptomycin at $37^{\circ} \mathrm{C}$ in an atmosphere containing $5 \% \mathrm{CO}_{2}$. Cells at the logarithmic growth phase were used for subsequent experiments.
RNA oligonucleotides and cell transfection. For the upregulation of miR-126 expression or the knockdown of PTPN9, RNA oligonucleotides were synthesized by Shanghai GenePharma, Ltd. (Shanghai, China). The sequences of the miR-126 mimics were as follows: Forward, 5'-UCGUACCGUGAGUAAUAA UGCG-3' and reverse, 5'-CAUUAUUACUCACGGUACGAU U-3'. The sequences of the PTPN9-siRNA were as follows: Forward, 5'-GUGGACAGUUCAGUACAAUTT-3' and reverse, 5'-AUUGUACUGAACUGUCCACTT-3'. The mock miRNA control sequences were forward, 5'-UUCUCCGAACGUGUC ACGUTT-3' and reverse, 5'-ACGUGACACGUUCGGAGA ATT-3'. Eca109 cells were treated with miR-126 mimics, mock, PTPN9-siRNA or equal amount of PBS (non-treated group) using Lipofectamine ${ }^{\circledR} 2000$ (Invitrogen; Thermo Fisher Scientific, Inc.) in OptiMEM I Reduced Serum media (Thermo Fisher Scientific, Inc.) at a final concentration of $100 \mathrm{pmol} / 10^{6}$ cells in all experiments. Cells were incubated with the complexes for $6 \mathrm{~h}$ prior to replacement of the medium. A fluorescence microscope was used to evaluate the transfection efficiency.

Reverse transcription-quantitative polymerase chain reaction $(R T$ - $q P C R)$. Total RNA was extracted using TRIzol ${ }^{\circledR}$ Reagent (Invitrogen; Thermo Fisher Scientific, Inc.). Reverse transcription and real-time PCR for miRNAs were conducted using the SYBR Green Hairpin-it ${ }^{\mathrm{TM}}$ miRNAs qPCR quantitation kit (Shanghai GenePharma, Ltd.) in $20 \mu \mathrm{l}$ reaction mixtures, and the reaction was performed on an ABI 7500 real-time PCR system (Applied Biosystems; Thermo Fisher Scientific, Inc.). The DNA was denatured at $95^{\circ} \mathrm{C}$ for $3 \mathrm{~min}$, followed by 40 amplification cycles consisting of $95^{\circ} \mathrm{C}$ for $12 \mathrm{sec}$ and $62^{\circ} \mathrm{C}$ for $40 \mathrm{sec}$. The primers for quantitative PCR were as follows: hsa-miR-126 forward, 5'-ACAGTTCTCTCGTACCGTGAG TAAT-3'; reverse, 5'-AAAGGTTGATCTGCTCTCTCT CTC-3'; human RNU6 forward, 5'-ATTGGAACGATACAG AGAGATT-3'; reverse, 5'-GGAACGTTCACGAATTTG-3'. The gene expression threshold cycle values of miRNAs were calculated by normalizing to the level of human U6 small nuclear RNA in the reaction.

For the analysis of mRNA, the SYBR Green RT-qPCR kit (Shanghai GenePharma, Inc.) was used for cDNA synthesis and $\mathrm{qPCR}$ according to the manufacturer's protocol. $\beta$-actin was used as an internal control and oligo (dT) was the common primer for reverse transcription. The sequences of the primers used for qPCR are as follows: PTPN9 forward, 5'-ATGTGC TCCGTGCCATAGAATTG-3'; reverse, 5'-GAGGATCTG AGAACGAAGAGGTTCC-3'; $\beta$-actin forward, 5'-TCTGGC ACCACACCTTCTAC-3'; reverse, 5'-GATAGCACAGCC TGGATAGC-3'. The thermocycler settings were the same as described previously. The $2^{-\Delta \Delta \mathrm{Cq}}$ method (31) was used for data analysis.

IHC and western blot analysis. Immunohistochemistry was performed as previously described (32). Rabbit anti-human PTPN9 antibody (dilution, 1:50; cat. no., sc-130859; Santa Cruz Biotechnology, Inc., USA) was used as the primary antibody, followed by a peroxidase-conjugated goat anti-rabbit secondary antibody (dilution, 1:200; cat. no., AB10058; Sangon Biotech Co., Ltd., Shanghai, China). Any intensity of cell membrane and cytoplasmic staining was considered a positive stain for PTPN9. Positive expression of protein was considered if the 
Table I. Expression of PTPN9 protein in patients with ESCC.

PTPN9 expression

\begin{tabular}{|c|c|c|c|c|}
\hline Group & No. of patients & Positive (\%) & Negative $(\%)$ & P-value \\
\hline Tumor tissue & 84 & $31(36.9)$ & $53(63.1)$ & 0.041 \\
\hline Normal tissue & 30 & $5(16.7)$ & $25(83.3)$ & \\
\hline
\end{tabular}

PTPN9, protein tyrosine phosphatase, non-receptor type 9; ESCC, esophageal squamous cell carcinoma

A

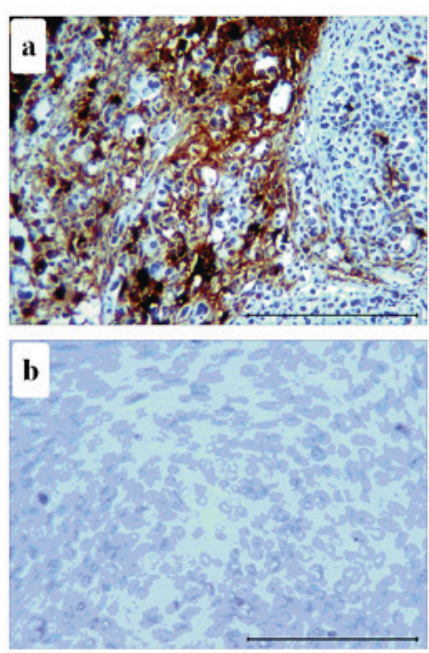

B

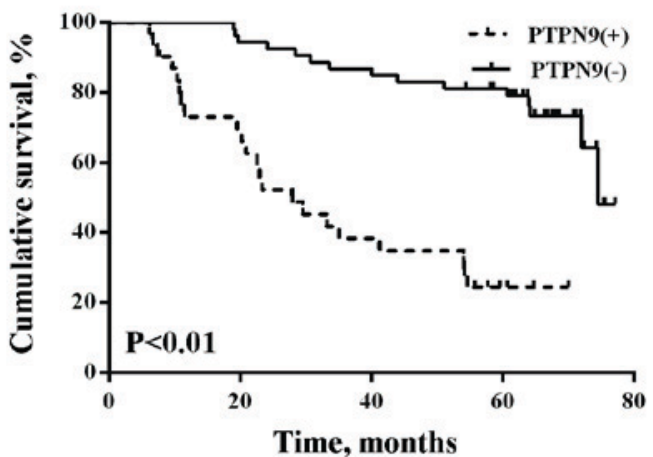

Time, months

Figure 1. PTPN9 protein expression in ESCC tissues compared with normal esophageal tissues and the association with prognosis in patients with ESCC. (A) Representative immunostaining images of PTPN9 in ESCC specimens and normal esophageal tissues (magnification, x200). a, ESCC specimens; b, normal esophagus tissues. Scale bar, $100 \mu \mathrm{m}$. (B) Kaplan-Meier survival analysis of patients with ESCC. Patients with PTPN9-positive tissues had a shorter survival time compared with those with PTPN9-negative tissues ( $<<0.01)$. PTPN9, protein tyrosine phosphatase, non-receptor type 9; ESCC, esophageal squamous cell carcinoma.

percentage of stained cells was $\geq 10 \%$. IHC results were further evaluated at high-power magnification (x200) once regions containing positive immunoreactivity were identified with low-power magnification (x40) using an optical microscope (BX41; Olympus Corporation, Tokyo, Japan). The section was examined by two pathologists individually.

Protein lysates were lysed on ice in cold radioimmunoprecipitation assay buffer containing a protease inhibitor cocktail (Pierce; Thermo Fisher Scientific, Inc.), according to the manufacturer's protocol. The protein concentration was determined using a bicinchoninic acid assay with a BCA protein assay kit (Beyotime Institute of Biotechnology, Haimen, China), equivalent amounts of protein (34 ug) were separated by SDS-PAGE on a $10 \%$ gel and blotted onto polyvinylidene fluoride membrane (Bio-Rad Laboratories, Inc., Hercules, CA, USA). Following blocking with 5\% non-fat milk in Tris-buffered saline containing $0.1 \%$ Tween-20 for $2 \mathrm{~h}$ at room temperature, the membranes were probed with primary antibodies against PTPN9, as previously described (dilution, 1:200), and $\beta$-actin (dilution, 1:5,000; cat. no., ab8227; Abcam, Cambridge, UK) at $4^{\circ} \mathrm{C}$ overnight. The bands were visualized using an enhanced chemiluminescence western blotting substrate (Thermo Fisher Scientific, Inc.), following incubation with the previously described secondary antibody (dilution,
1:5,000) for $2 \mathrm{~h}$ at room temperature. The internal control $\beta$-actin was used for normalization. Protein bands were quantified using FluorChem FC3 AlphaView software (version 2.0; ProteinSimple, San Jose, CA, USA).

Prediction of miRNA targets. PicTar (http://pictar .mdc-berlin.de/), Targetscan (http://www.targetscan.org/) and Microcosm Targets (http://www.ebi.ac.uk/enright-srv/microcosm/htdocs/targets/v5/) were searched to predict potential targets for miR-126. The 3'-untranslated region of PTPN9 mRNA (RefSeq NM_002833) was identified as containing a putative miRNA-126 binding site.

Cell proliferation assay. The miR-126 mimic, mock control and PTPN9-siRNA were transfected into Eca109 cells at a concentration of $100 \mathrm{pmol} / 10^{6}$ cells. A total of $24 \mathrm{~h}$ later, following trypsinization, cells were counted and seeded into 96 -well plates $\left(5 \times 10^{3}\right.$ cells/well $)$ in quadruplicate. Cell proliferation was monitored at 5, 24, 48, 72 and $96 \mathrm{~h}$ following transfection using the Cell Counting Kit-8 (Dojindo Molecular Technologies, Inc., Kumamoto, Japan), according to the manufacturer's protocol. The number of cells was evaluated through measurement of absorbance at $450 \mathrm{~nm}$ using a Wellscan MK-3 (Labsystems Dragon, Helsinki, Finland). 
Table II. Association between PTPN9 Expression and clinicopathological features in patients with ESCC.

\begin{tabular}{|c|c|c|c|c|}
\hline \multirow[b]{2}{*}{ Features } & \multirow[b]{2}{*}{ No of patients } & \multicolumn{2}{|c|}{ PTPN9 expression } & \multirow[b]{2}{*}{ P-value } \\
\hline & & Positive, $\mathrm{n}=31(\%)$ & Negative, $\mathrm{n}=53(\%)$ & \\
\hline \multicolumn{5}{|l|}{ Age, years } \\
\hline$\leq 60$ & 49 & $16(32.7)$ & $33(67.3)$ & 0.339 \\
\hline$>60$ & 35 & $15(42.9)$ & $20(57.1)$ & \\
\hline \multicolumn{5}{|l|}{ Sex } \\
\hline Male & 58 & $21(36.2)$ & $37(63.8)$ & 0.834 \\
\hline Female & 26 & $10(38.5)$ & $16(61.5)$ & \\
\hline \multicolumn{5}{|c|}{ Tumor location } \\
\hline Upper & 12 & $5(41.7)$ & $7(58.3)$ & 0.418 \\
\hline Middle & 58 & $23(39.7)$ & $35(60.3)$ & \\
\hline Lower & 14 & $3(21.4)$ & $11(78.6)$ & \\
\hline \multicolumn{5}{|c|}{ Maximum tumor size } \\
\hline$\leq 3$ & 51 & $22(43.1)$ & $29(56.9)$ & 0.141 \\
\hline$>3$ & 33 & $9(27.3)$ & $24(72.7)$ & \\
\hline \multicolumn{5}{|c|}{ Differentiation } \\
\hline Poor & 28 & $15(53.6)$ & $13(46.4)$ & 0.058 \\
\hline Moderate & 37 & $12(32.4)$ & $25(67.6)$ & \\
\hline Well & 19 & $4(21.1)$ & $15(78.9)$ & \\
\hline \multicolumn{5}{|c|}{$\mathrm{T}$ classification } \\
\hline $\mathrm{T} 1+\mathrm{T} 2$ & 39 & $9(23.1)$ & $30(76.9)$ & 0.014 \\
\hline$\geq \mathrm{T} 3$ & 45 & $22(48.9)$ & $23(51.1)$ & \\
\hline \multicolumn{5}{|c|}{$\mathrm{N}$ classification } \\
\hline Yes & 27 & $16(59.3)$ & $11(40.7)$ & 0.003 \\
\hline No & 57 & $15(26.3)$ & $42(73.7)$ & \\
\hline \multicolumn{5}{|l|}{ TNM stage } \\
\hline $\mathrm{I}+\mathrm{II}$ & 64 & 17 (26.6) & $47(73.4)$ & 0.001 \\
\hline$>$ III & 20 & $14(70.0)$ & $6(30.0)$ & \\
\hline \multicolumn{5}{|c|}{ Postoperative chemotherapy } \\
\hline Yes & 34 & $11(32.4)$ & $23(67.6)$ & 0.476 \\
\hline No & 50 & $20(40.0)$ & $30(60.0)$ & \\
\hline \multicolumn{5}{|c|}{ Postoperative recurrence } \\
\hline Yes & 9 & $4(44.4)$ & $5(55.6)$ & 0.896 \\
\hline No & 75 & $27(36.0)$ & $48(64.0)$ & \\
\hline
\end{tabular}

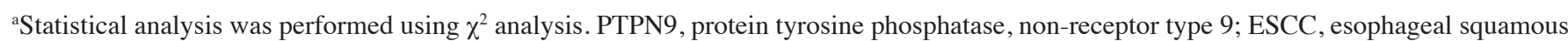
cell carcinoma.

Transwell cell invasion assay. Transwell inserts coated with Matrigel (Corning Incorporated, Corning, NY, USA) were used for a cell invasion assay. Cells transfected with miR-126 mimics, mock controls and PTPN9-siRNA for $24 \mathrm{~h}$ were detached and resuspended in serum-free medium. A $200 \mu 1$ suspension containing $5 \times 10^{4}$ cells was added to the upper insert. RPMI-1640 containing 20\% FBS was added to the lower wells in the 6 -well cell culture plate as a chemoattractant. Following a 24-h incubation, cells were fixed in $4 \%$ paraformaldehyde for $15 \mathrm{~min}$ and stained with $1 \%$ crystal violet for $10 \mathrm{~min}$ at room temperature. The cells on the upper surface of filter were wiped off with a cotton swab and invaded cells on the lower surface of the membrane were visualized with an optical microscope in 5 fields of view at $\times 200$ magnification.

Cell apoptosis analysis. At $48 \mathrm{~h}$ following transfection, cells were washed and resuspended in binding buffer at a final concentration of $1 \times 10^{6}$ cells $/ \mathrm{ml}$, and $100 \mu \mathrm{l}$ cell suspension was incubated with $10 \mu \mathrm{l}$ Annexin V-fluorescein isothiocyanate (FITC) and $5 \mu \mathrm{l}$ propidium iodide (PI) in the dark for 15 min using the Annexin V-FITC kit (Miltenyi Biotec $\mathrm{GmbH}$, Bergisch Gladbach, Germany), according to the manufacturer's protocol. The stained cells were analyzed using flow cytometry (FACSCalibur $^{\text {TM }}$; BD Biosciences, Franklin Lakes, 
Table III. Multivariate analysis of PTPN9 expression status with regard to OS in patients with ESCC.

\begin{tabular}{lrrrrr}
\hline & \multicolumn{5}{c}{ OS } \\
\cline { 2 - 6 } Variables & \multicolumn{1}{c}{$\beta$} & SE & Wald & HR (95\% CI) & P-value \\
\hline Differentiation & -0.734 & 0.285 & 6.610 & $0.480(0.274-0.840)$ & 0.010 \\
TNM stage & 1.536 & 0.367 & 17.487 & $4.646(2.261-9.543)$ & 0.001 \\
PTPN9, positive vs. negative & 1.087 & 0.388 & 7.867 & $2.967(1.388-6.342)$ & 0.005 \\
Postoperative chemotherapy & 1.102 & 0.511 & 4.464 & $3.010(1.105-8.196)$ & 0.031 \\
Postoperative recurrence & -1.465 & 0.432 & 11.497 & $0.231(0.099-0.539)$ & 0.001 \\
\hline
\end{tabular}

SE, standard error; HR, hazard ratio; CI, confidence interval; OS, overall survival; TNM, tumor-node-metastasis; PTPN9, protein tyrosine phosphatase, non-receptor type 9; ESCC, esophageal squamous cell carcinoma.

NJ, USA). Annexin V-FITC-positive and PI-negative staining was indicative of cells undergoing early apoptosis, and the percentage of apoptotic cells of each group was compared.

Statistical analysis. Quantitative data were expressed as the mean \pm standard deviation and were statistically analyzed by t-test. Pearson's $\chi^{2}$ test was used to analyze the association between PTPN9 expression levels and the clinicopathological features of ESCC specimens. Survival curves were calculated using the Kaplan-Meier method, and compared using the Log-rank test. The influence of each clinicopathological parameter on survival was assessed through multivariate regression analysis with the Cox proportional hazards regression model. A Wald test was used to test the association of each variable in Table II with overall survival. All data were analyzed using SPSS software (17.0; SPSS, Inc., Chicago, IL, USA). $\mathrm{P}<0.05$ was considered to indicate a statistically significant difference.

\section{Results}

PTPN9 overexpression in ESCC specimens. A total of 84 ESCC specimens were obtained for an IHC assay to analyze the expression of PTPN9 in ESCC. The data revealed that positive PTPN9 staining was observed in $36.9 \%$ (31/84) of tumor tissues, and in $16.7 \%$ of normal specimens (5/30; Table I), suggesting that the positive rate of PTPN9 in tumor specimens was increased compared with healthy tissues (Fig. 1A).

PTPN9 protein expression and clinicopathological features of ESCC. The association between PTPN9 expression levels and patient clinicopathological features is presented in Table II. According to the expression levels of PTPN9 protein, clinical data were divided into two groups, the PTPN9-positive and PTPN9-negative staining group. As presented in Table II, PTPN9 was overexpressed in patients with increased T classification $(\mathrm{P}=0.014), \mathrm{N}$ classification $(\mathrm{P}=0.003)$ and TNM stage $(\mathrm{P}<0.001)$. No significant association was detected between PTPN9 expression levels and other clinicopathological features, including patient age, sex and tumor location (Table II).

PTPN9 expression is negatively correlated with the survival time of patients with ESCC. The median follow-up time was
60.7 months (range, 6.1-77.17), Kaplan-Meier analysis survival curves revealed that patients with PTPN9-negative expression had a longer overall survival compared with PTPN9-positive group (log-rank test, $\mathrm{P}<0.01$; Fig. 1B). The results of multivariate Cox proportional hazards regression analysis demonstrated that PTPN9 protein expression, differentiation, TNM stage, postoperative chemotherapy and postoperative recurrence were independent prognostic markers for patients with ESCC (Table III).

PTPN9 protein expression level, and not mRNA level, is altered with the upregulation of miR-126 expression. As PTPN9 was identified as a putative target for miR-126 (Fig. 2A), it was assessed whether miR-126 regulates endogenous PTPN9 expression by transfecting an miR-126 mimic into Eca109 cells. miR-126 and PTPN9 mRNA expression levels were assessed with RT-qPCR. Following transfection, the expression level of miR-126 was $~ 9$-fold higher compared with the NC group (Fig. 2B). A decreasing trend in PTPN9 mRNA expression level in cells transfected with miR-126 mimics was observed; however, it was not statistically significant (Fig. 2C).

The expression of PTPN9 protein level was also observed in Eca109 cells transfected with miR-126 mimics. An increase of miR-126 level was significantly associated with a decrease in PTPN9 protein expression level as determined by western blot $(\mathrm{P}<0.05$; Fig. 2D). No significant differences were observed in the expression of PTPN9 mRNA, miR-126 and PTPN9 protein expression between the mock and NC groups (Fig. 2B, C and D). Taken together, these results indicated that PTPN9 was targeted by miR-126 and the expression of PTPN9 in Eca109 cells was negatively regulated by miR-126.

PTPN9 depletion inhibits cell proliferation and invasion in Ecal09 cells, but has no effect on apoptosis. PTPN9-siRNA was used for inhibiting the expression of PTPN9 to assess its effect on ESCC cells. In the PTPN9-siRNA group, the expression level of PTPN9 was $\sim 50 \%$ lower compared with the NC group, as detected using RT-qPCR (Fig. 2C). CCK-8 and Transwell assays as well as flow cytometry were used to examine the impacts of PTPN9 on cell proliferation, invasion and apoptosis in Eca109 cells. The results revealed that the knockdown of PTPN9 significantly inhibited cell proliferation at $48(\mathrm{P}<0.05), 72(\mathrm{P}<0.01)$ and $96 \mathrm{~h}(\mathrm{P}<0.01)$ after transfection 

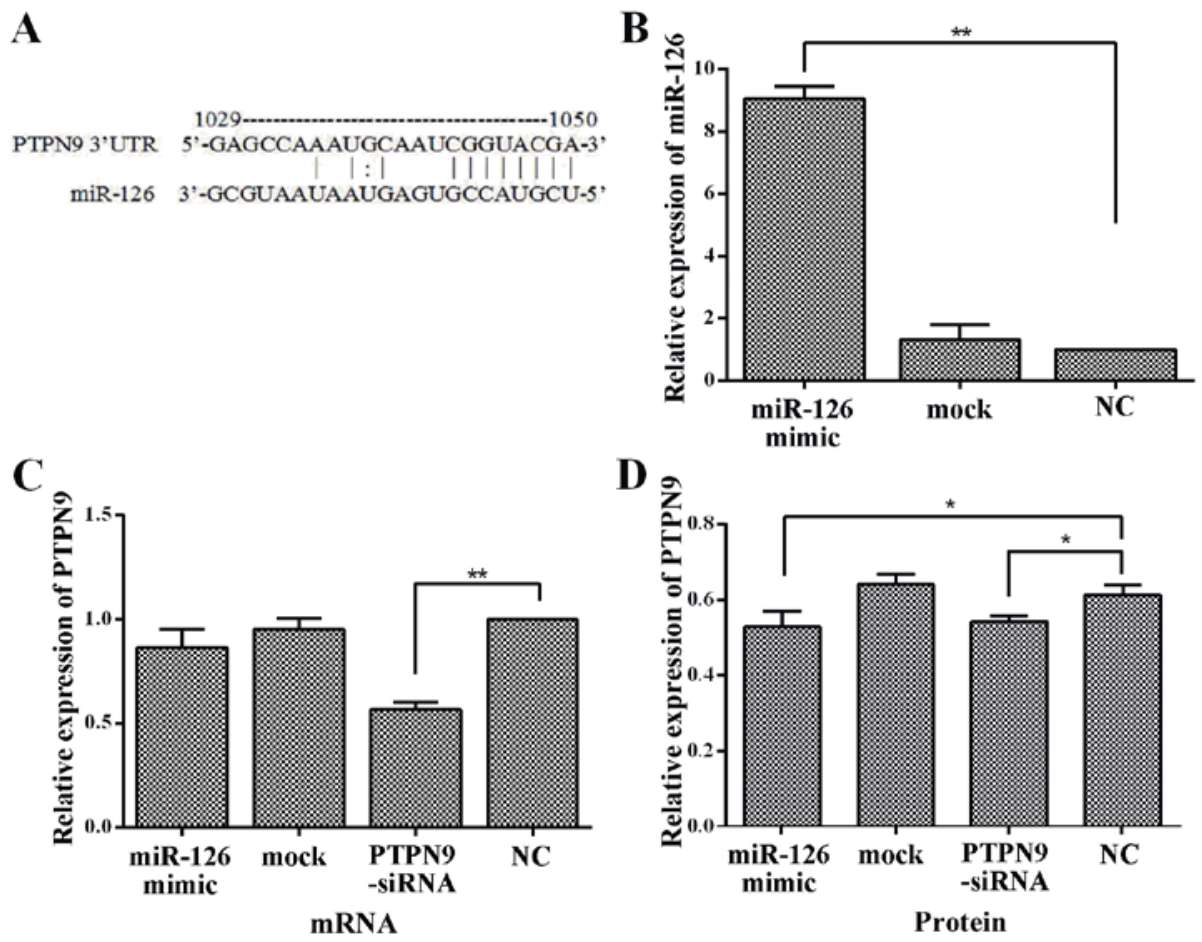

Figure 2. PTPN9 as a potential target for miR-126. (A) Predicted complementary sequences between miR-126 and PTPN9. (B) Detection of the relative expression of miR-126 in Eca109 cells following transfection with miRNA-126 mimics and mock controls. (C) Reverse transcription-quantitative polymerase chain reaction analysis of PTPN9 mRNA in Eca109 cells following transfection with PTPN9-siRNA, mock control or miR-126 mimics. * P<0.01. (D) Quantification of the western blot analysis of PTPN9 protein levels in Eca109 cells following transfection with miR-126 mimics, mock control or PTPN9-siRNA. "P<0.05. PTPN9, protein tyrosine phosphatase, non-receptor type 9; miR-126, microRNA-126; NC, negative control; siRNA, small interfering RNA.

(Fig. 3A). A decrease in the number of cells migrating through the Matrigel was also observed (Fig. 3B and C). However, no significant difference in apoptotic rate was identified between any two groups (Fig. 3D and E). These results indicated that PTPN9 may serve an important role in the cell proliferation and invasion of ESCC.

\section{Discussion}

Esophageal cancer is a global health challenge, with 5-year overall survival ranging between 15 and 35\% (33). Therefore, novel molecular markers used to predict the progression and prognosis of ESCC are required. In the last few years, a number of studies have revealed that a variety of human diseases are associated with aberrant expression of PTPN9 $(34,35)$. However, the role of PTPN9 in ESCC remains to be elucidated. The present study revealed that the protein expression rate of PTPN9 is increased in ESCC specimens compared with healthy esophageal tissues using IHC analysis. Furthermore, the protein levels of PTPN9 were associated with various clinicopathological parameters, including $\mathrm{T}$ classification, $\mathrm{N}$ classification and TNM stage. Multivariate Cox regression analyses revealed that PTPN9 is an independent prognostic predictor for patients with ESCC.

A previous study indicated that knockdown of PTPN9 in the liver of diabetic mice was able to lead to insulin sensitization and normalization of hyperglycemia (12). In addition, it has been demonstrated that PTPN9 is able to negatively regulate the VEGF-induced cell signal through inhibition of the phosphorylation of VEGF receptor 2 on Tyr1175 in endothelial cells (16). Furthermore, it has been reported that PTPN9 is able to inhibit ErbB2 and epidermal growth factor receptor (EGFR) signaling by dephosphorylating ErbB2/EGFR to impair growth and invasiveness in breast cancer cells (13), supported by the results of Du et al (15). In the present study, PTPN9 was observed to be overexpressed in ESCC specimens, compared with healthy esophageal tissues, indicating that PTPN9 may be an oncogene during the development of ESCC. To evaluate this hypothesis, the PTPN9 depletion cell model was constructed following transfection of PTPN9-siRNA into the Eca109 ESCC cell line. As expected, cell proliferation and invasion was significantly suppressed upon the knockdown of PTPN9.

A number of previous studies have demonstrated that aberrant expression of miRNAs serves a key role in the tumorigenic process $(26,36)$. Therefore, an improved understanding of the underlying mechanisms of these non-coding RNAs may improve technologies for the diagnosis and treatment of human diseases. A previous study reported that miR-126 was able to regulate PTPN9 in the hematopoietic differentiation of human embryonic stem cells at the post-transcriptional level (29). Frequently described as a tumor suppressor in a number of studies, miR-126 was observed to be downregulated in ESCC tissues and cell lines $(32,37-39)$. However, the interaction between miR-126 and PTPN9 in the process of ESCC remains to be established. In the present study, using the miRNA target prediction program, a putative miR-126 binding site was identified within the 3'UTR of PTPN9, suggesting that PTPN9 may be a target of miR-126. The present study also revealed that ectopic expression of miR-126 reduced the levels of PTPN9, 
A

CCK-8

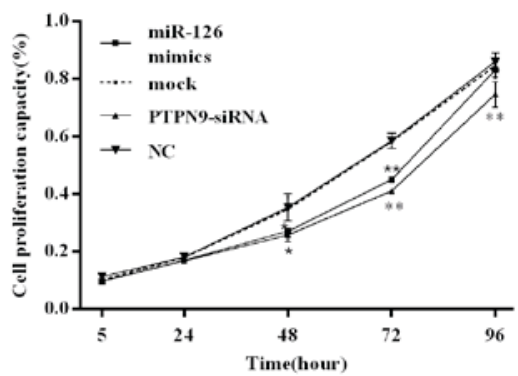

B

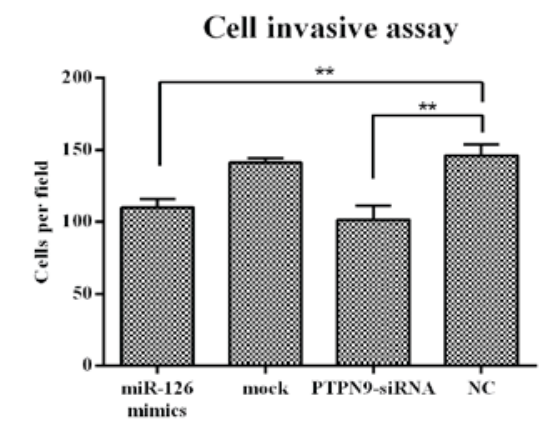

D

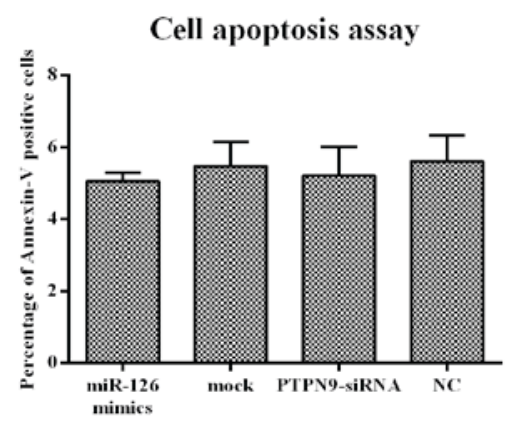

C

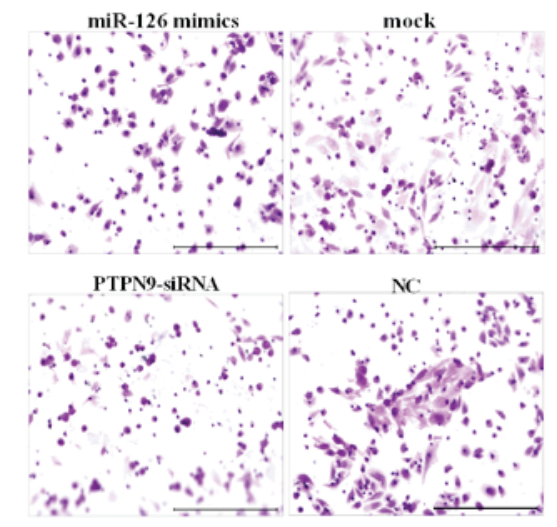

E
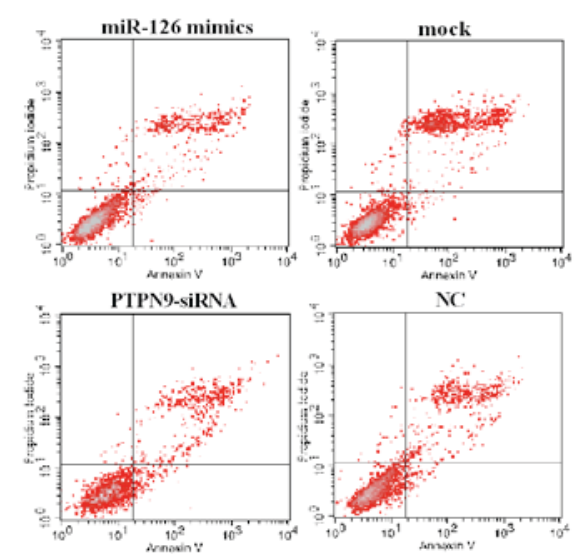

Figure 3. Knockdown of PTPN9 inhibited ESCC cell proliferation and invasion, but not apoptosis. (A) CCK-8 analysis of Eca109 cell growth following transfection with PTPN9-siRNA, mock control or miR-126 mimics. ${ }^{*} \mathrm{P}<0.05,{ }^{* *} \mathrm{P}<0.01$ compared with NC. (B) Quantification of invasion data. ${ }^{* *} \mathrm{P}<0.01$. (C) Transwell analysis of Eca109 cell invasion following transfection with PTPN9-siRNA, mock control or miR-126 mimics (stained with crystal violet). Scale bar, $100 \mu \mathrm{m}$. (D) Quantification of apoptosis data. (E) Apoptotic analysis of Eca109 cells using flow cytometry following transfection with PTPN9-siRNA, mock control and miR-126 mimics. miR-126, microRNA-126; ESCC, esophageal squamous cell carcinoma; PTPN9, protein tyrosine phosphatase, non-receptor type 9; CCK-8, cell counting kit-8; siRNA, small interfering RNA; NC, negative control; UTR, untranslated region.

and inhibited the growth and invasion of Eca109 cells, similar to the results from the PTPN9-siRNA group. These results indicate that miR-126 may be an important component of the signal pathway induced by PTPN9 in ESCC.

However, the present study has certain limitations. The sample size of patients with ESCC was relatively small; therefore, studies with a larger sample size may be conducted in order to further identify the prognostic impact of each clinicopathological factor on survival time at various clinical stages. In addition, a dual-luciferase reporter assay may be used to examine the direct targets of PTPN9.

In conclusion, the present study demonstrated that PTPN9 expression levels are associated with T classification,
$\mathrm{N}$ classification and TNM stage, and may represent a useful prognostic marker for patients with ESCC. Through being regulated by miR-126, downregulation of PTPN9 may inhibit growth and decrease the invasive capacity of ESCC cells, indicating that PTPN9 may be a promising molecular therapeutic target for ESCC in the future.

\section{Acknowledgements}

The present study was supported by the Research Fund of the National Key Clinical Specialty of China and the Innovation Foundation of Excellent Intellectuals of Henan Province (grant no. 20070214). 


\section{References}

1. Torre LA, Bray F, Siegel RL, Ferlay J, Lortet-Tieulent J and Jemal A: Global cancer statistics, 2012. CA Cancer J Clin 65: 87-108, 2015.

2. Chen WQ, Zheng RS, Zhang SW, Zeng HM and Zou XN: The incidences and mortalities of major cancers in China, 2010. Chin J Cancer 33: 402-405, 2014.

3. Lin Y, Totsuka Y, He Y, Kikuchi S, Qiao Y, Ueda J, Wei W, Inoue $\mathrm{M}$ and Tanaka $\mathrm{H}$ : Epidemiology of esophageal cancer in Japan and China. J Epidemiol 23: 233-242, 2013.

4. Matsushima K, Isomoto H, Kohno S and Nakao K: MicroRNAs and esophageal squamous cell carcinoma. Digestion 82: 138-144, 2010.

5. Kruger JM, Fukushima T, Cherepanov V, Borregaard N, Loeve C, Shek C, Sharma K, Tanswell AK, Chow CW and Downey GP: Protein-tyrosine phosphatase MEG2 is expressed by human neutrophils. Localization to the phagosome and activation by polyphosphoinositides. J Biol Chem 277: 2620-2628, 2002.

6. Xu MJ, Sui X, Zhao R, Dai C, Krantz SB and Zhao ZJ: PTP-MEG2 is activated in polycythemia vera erythroid progenitor cells and is required for growth and expansion of erythroid cells. Blood 102: 4354-4360, 2003.

7. Huynh H, Wang X, Li W, Bottini N, Williams S, Nika K, Ishihara H, Godzik A and Mustelin T: Homotypic secretory vesicle fusion induced by the protein tyrosine phosphatase MEG2 depends on polyphosphoinositides in T cells. J Immunol 171: 6661-6671,2003.

8. Krugmann S, Anderson KE, Ridley SH, Risso N, McGregor A, Coadwell J, Davidson K, Eguinoa A, Ellson CD, Lipp P, et al: Identification of ARAP3, a novel PI3K effector regulating both Arf and Rho GTPases, by selective capture on phosphoinositide affinity matrices. Mol Cell 9: 95-108, 2002.

9. Zhang D, Marlin MC, Liang Z, Ahmad M, Ashpole NM, Sonntag WE, Zhao ZJ and Li G: The protein tyrosine phosphatase MEG2 regulates the transport and signal transduction of tropomyosin receptor kinase A. J Biol Chem 291: 23895-23905, 2016.

10. Huynh H, Bottini N, Williams S, Cherepanov V, Musumeci L, Saito K, Bruckner S, Vachon E, Wang X, Kruger J, et al: Control of vesicle fusion by a tyrosine phosphatase. Nat Cell Biol 6: 831-839, 2004

11. Cho CY, Koo SH, Wang Y, Callaway S, Hedrick S, Mak PA, Orth AP, Peters EC, Saez E, Montminy M, et al: Identification of the tyrosine phosphatase PTP-MEG2 as an antagonist of hepatic insulin signaling. Cell Metab 3: 367-378, 2006.

12. Zhang S, Liu S, Tao R, Wei D, Chen L, Shen W, Yu ZH, Wang L, Jones DR, Dong XC and Zhang ZY: A highly selective and potent PTP-MEG2 inhibitor with therapeutic potential for type 2 diabetes. J Am Chem Soc 134: 18116-18124, 2012.

13. Yuan T, Wang Y, Zhao ZJ and Gu H: Protein-tyrosine phosphatase PTPN9 negatively regulates ErbB2 and epidermal growth factor receptor signaling in breast cancer cells. J Biol Chem 285 14861-14870, 2010.

14. Su F, Ren F, Rong Y, Wang Y, Geng Y, Wang Y, Feng M, Ju Y, Li Y, Zhao ZJ, et al: Protein tyrosine phosphatase Meg2 dephosphorylates signal transducer and activator of transcription 3 and suppresses tumor growth in breast cancer. Breast Cancer Res 14: R38, 2012.

15. Du WW, Fang L, Li M, Yang X, Liang Y, Peng C, Qian W, O'Malley YQ, Askeland RW, Sugg SL, et al: MicroRNA miR-24 enhances tumor invasion and metastasis by targeting PTPN9 and PTPRF to promote EGF signaling. J Cell Sci 126: 1440-1453, 2013.

16. Hao Q, Samten B, Ji HL, Zhao ZJ and Tang H: Tyrosine phosphatase PTP-MEG2 negatively regulates vascular endothelial growth factor receptor signaling and function in endothelial cells. Am J Physiol Cell Physiol 303: C548-C553, 2012.

17. Hromadnikova I, Kotlabova K, Hympanova L and Krofta L: Gestational hypertension, preeclampsia and intrauterine growth restriction induce dysregulation of cardiovascular and cerebrovascular disease associated microRNAs in maternal whole peripheral blood. Thromb Res 137: 126-140, 2016

18. Gu L, Li H, Chen L, Ma X, Gao Y, Li X, Zhang Y, Fan Y and Zhang X: MicroRNAs as prognostic molecular signatures in renal cell carcinoma: A systematic review and meta-analysis. Oncotarget 6: 32545-32560, 2015.

19. Meister J and Schmidt MH: miR-126 and miR-126*: New players in cancer. ScientificWorldJournal 10: 2090-2100, 2010.
20. Shang AQ, Xie YN, Wang J, Sun L, Wei J, Lu WY, Lan JY, Wang WW, Wang L and Wang LL: Predicative values of serum microRNA-22 and microRNA-126 levels for non-small cell lung cancer development and metastasis: A case-control study. Neoplasma 64, 2017. (Epub ahead of print).

21. Yuan W, Guo YQ, Li XY, Deng MZ, Shen ZH, Bo CB, Dai YF, Huang MY, Yang ZY, Quan YS, et al: MicroRNA-126 inhibits colon cancer cell proliferation and invasion by targeting the chemokine (C-X-C motif) receptor 4 and Ras homolog gene family, member A, signaling pathway. Oncotarget 7 : 60230-60244, 2016.

22. Wang CZ, Yuan P and Li Y: MiR-126 regulated breast cancer cell invasion by targeting ADAM9. Int J Clin Exp Pathol 8: 6547-6553, 2015

23. Jiang R, Zhang C, Liu G, Gu R and Wu H: MicroRNA-126 inhibits proliferation, migration, invasion and EMT in osteosarcoma by targeting ZEB1. J Cell Biochem, 2017 (Epub ahead of print).

24. Wang J, Zhou Y, Fei X, Chen X, Yan J, Liu B and Zhu Z: ADAM9 functions as a promoter of gastric cancer growth which is negatively and post-transcriptionally regulated by miR-126. Oncol Rep 37: 2033-2040, 2017.

25. Zhu X, Li H, Long L, Hui L, Chen H, Wang X, Shen H and $\mathrm{Xu}$ W: miR-126 enhances the sensitivity of non-small cell lung cancer cells to anticancer agents by targeting vascular endothelial growth factor A. Acta Biochim Biophys Sin (Shanghai) 44: 519-526, 2012.

26. Png KJ, Halberg N, Yoshida M and Tavazoie SF: A microRNA regulon that mediates endothelial recruitment and metastasis by cancer cells. Nature 481: 190-194, 2011.

27. Li Z, Li N, Wu M, Li X, Luo Z and Wang X: Expression of miR-126 suppresses migration and invasion of colon cancer cells by targeting CXCR4. Mol Cell Biochem 381: 233-242, 2013.

28. Yue S, Shi H, Han J, Zhang T, Zhu W and Zhang D: Prognostic value of microRNA-126 and CRK expression in gastric cancer. Onco Targets Ther 9: 6127-6135, 2016.

29. Huang X, Gschweng E, Van Handel B, Cheng D, Mikkola HK and Witte ON: Regulated expression of microRNAs-126/126 inhibits erythropoiesis from human embryonic stem cells. Blood 117: 2157-2165, 2011

30. Wittekind C: 2010 TNM system: On the 7th edition of TNM classification of malignant tumors. Pathologe 31: 331-332, 2010.

31. Livak KJ and Schmittgen TD: Analysis of relative gene expression data using real-time quantitative PCR and the 2(-Delta Delta $\mathrm{C}(\mathrm{T}))$ method. Methods 25: 402-408, 2001

32. Li H, Meng F, Ma J, Yu Y, Hua X, Qin J and Li Y: Insulin receptor substrate-1 and Golgi phosphoprotein 3 are downstream targets of miR126 in esophageal squamous cell carcinoma. Oncol Rep 32: 1225-1233, 2014.

33. Domper Arnal MJ, Ferrández Arenas Á and Lanas Arbeloa Á Esophageal cancer: Risk factors, screening and endoscopic treatment in Western and Eastern countries. World J Gastroenterol 21: 7933-7943, 2015

34. Hu B, Yan X, Liu F, Zhu C, Zhou H, Chen Y, Liu J, Gu X, Ni R and Zhang T: Downregulated expression of PTPN9 contributes to human hepatocellular carcinoma growth and progression. Pathol Oncol Res 22: 555-565, 2016.

35. Hong Y, Liang H, Uzair-Ur-Rehman, Wang Y, Zhang W, Zhou Y, Chen S, Yu M, Cui S, Liu M, et al: miR-96 promotes cell proliferation, migration and invasion by targeting PTPN9 in breast cancer. Sci Rep 6: 37421, 2016.

36. Rupaimoole R, Calin GA, Lopez-Berestein G and Sood AK: miRNA deregulation in cancer cells and the tumor microenvironment. Cancer Discov 6: 235-246, 2016.

37. Nie ZC, Weng WH, Shang YS, Long Y, Li J, Xu YT and Li Z: MicroRNA-126 is down-regulated in human esophageal squamous cell carcinoma and inhibits the proliferation and migration in EC109 cell via PI3K/AKT signaling pathway. Int J Clin Exp Pathol 8: 4745-4754, 2015.

38. Liu R, Gu J, Jiang P, Zheng Y, Liu X, Jiang X, Huang E, Xiong S, Xu F, Liu G, et al: DNMT1-microRNA126 epigenetic circuit contributes to esophageal squamous cell carcinoma growth via ADAM9-EGFR-AKT signaling. Clin Cancer Res 21: 854-863, 2015.

39. Liu SG, Qin XG, Zhao BS, Qi B, Yao WJ, Wang TY, Li HC and $\mathrm{Wu} \mathrm{XN}$ : Differential expression of miRNAs in esophageal cancer tissue. Oncol Lett 5: 1639-1642, 2013. 